\title{
JOURNAL.RU
}

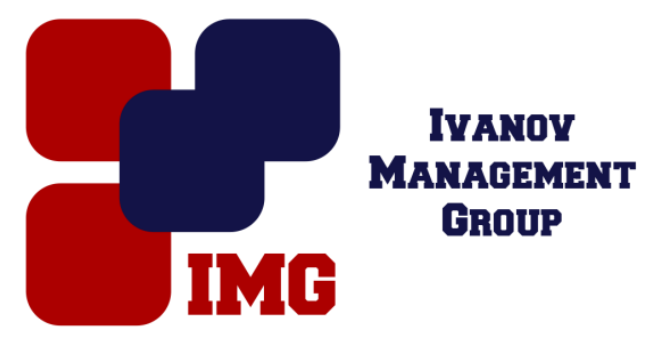

Кажибаева Г.Е., Туребеков Т.А.

Многопрофильный колледж гражданской защитыь

Кокшетау, Казахстан

Министерство Внутренних дел Республики

Астана, Казахстан

doi: $10.18411 / 1 \mathrm{j}-31-07-2017-43$

idsp 000001:1j-31-07-2017-43

\section{Выдвижение версий и планирование расследования}

\begin{abstract}
Аннотация
В данной статье рассматривается выдвижение версий и планирование расследования. Одним из важнейших условий успешного расследования каждого преступления является планирование расследования. Планирование, являющееся одним из обязательных условий расследования преступлений, представляет сложный мыслительный процесс, заключающийся в определении задач следствия, путей и способов их решения в соответствии с требованиями закона, результаты которой, как правило, отражаются в письменных планах расследования.

Ключевые слова: планирование расследования, выдвижение версий, этап расследования, работа следователя, планирования расследования преступлений.

\section{Abstract}

In this article promotion of versions and planning of investigation is considered. One of the most important conditions of successful investigation of each crime is investigation planning. The planning which is one of indispensable conditions of investigation of crimes represents the difficult thought process consisting in definition of problems of the investigation, ways and ways of their decision according to requirements of the law which results, as a rule, are reflected in written plans of investigation.

Keywords: investigation planning, promotion of versions, investigation stage, work of the investigator, planning of investigation of crimes.
\end{abstract}


Одним из важнейших условий успешного расследования каждого преступления является планирование расследования. Планирование расследования позволяет наиболее целенаправленно организовать процесс исследования, способствует объективности, полноте и всесторонности проверки выдвинутых версий, установлении фактических обстоятельств, розыска и изобличения виновных.

Планирование, являющееся одним из обязательных условий расследования преступлений, представляет сложный мыслительный процесс, заключающийся в определении задач следствия, путей и способов их решения в соответствии с требованиями закона, результаты которой, как правило, отражаются в письменных планах расследования.

Планирования расследования преступлений имеет большое значение:

1) Планирование позволяет наиболее рационально распределить время, достигать экономичности и оперативности в работе;

2) Планирование способствует объективности, полноте и всесторонности следствия, позволяет наиболее эффективно сочетать следственные действия, оперативно - розыскные и организационные мероприятия, использовать техникокриминалистические средства;

3) Планирование дисциплинирует следователя, письменный план расследования является для следователя и оперативного работника средством самоконтроля;

4) Планирование позволяет контролировать работу следователя.

Успешное решение задачи повышения эффективности процесса предварительного расследования во многом зависит от совершенствования планирования и организации расследования по конкретным уголовным делам, находящимся в производстве следователей.

В содержание деятельности по планированию расследования входят следующие элементы:

- выбор направления расследования посредством выдвижения следственных версий;

- определение задач расследования и их конкретизация путем установления предмета и пределов доказывания, а также сопутствующих предмету доказывания обстоятельств, выяснение которых необходимо для достижения истины; 
- определение круга следственных и иных действий, организационных и технических мероприятий, необходимых для решения поставленных задач и проверки выдвинутых версий;

- установление содержания и определение тактики каждого из намеченных следственных действий;

- установление последовательности проведения намеченных действий и сроков их производства;

- решение вопроса об исполнителях запланированных действий;

- оформление намеченной программы: составление плана расследования и различного вида схем, графиков, карточек.

Планирование является непременным условием качественного расследования, осуществляемого в установленные законом сроки. Посредством планирования расследование приобретает целенаправленный характер, создаются предпосылки для отыскания правильных путей решения поставленных задач, выбора эффективных тактических приемов и использования всех имеющихся технико-криминалистических средств.

Особо важное значение деятельность по планированию, расследованию приобретает в процессе работы по сложным уголовным делам, требующим координации усилий не только следователей, но и работников других служб органов внутренних дел. Продуманное и целенаправленное объединение в этом случае действий ряда подразделений и служб находит отражение в самой структуре плана расследования: по каждой его позиции устанавливается ответственность конкретного лица за исполнение соответствующего планового мероприятия.

Планирование тесно связано с организацией расследования по конкретному делу. Под организацией расследования в данном случае понимается комплекс мер, направленных на создание оптимальных условий для осуществления конкретных актов расследования. Если сущность планирования заключается в том, чтобы правильно наметить программу действий следователя, то существо организаторской деятельности - в обеспечении реализации намеченного плана.

Постоянное совершенствование планирования расследования продолжает оставаться одной из актуальных задач, стоящих перед следственным аппаратом органов внутренних дел. Анализ этой деятельности должен осуществляться с учетом основных принципов планирования расследования. 
Принцип научности планирования означает, что при составлении плана расследования должны учитываться следующие обстоятельства:

- закономерности процесса познания в расследовании, рекомендации криминалистики по использованию средств и приемов обнаружения, изъятия, сохранения и использования доказательств;

- возможности использования достижений науки в области исследования различных объектов, которые могут быть вещественными доказательствами по делу, специальные технические возможности обнаружения и фиксации доказательств;

- эффективное использование научно-технических средств, правильное сочетание следственных действий с оперативнорозыскными мерами, взаимодействия следователя с оперативными подразделениями, предполагающее взаимную информацию и координацию действий.

Принцип реальности расследования выражается, прежде всего, в обоснованности, реальности следственных версий, как при их выдвижении, так и при дальнейшем анализе, в существующей возможности логически выводимых из них следствий, а также в практической выполнимости намеченных для их проверки мероприятии и сроков выполнения.

Принцип динамичности означает, что эта деятельность не является разовым актом. Она осуществляется постоянно по мере поступления соответствующей информации на протяжении всего процесса расследования. Планы расследования не должны рассматриваться как неизменные; они постоянно уточняются, дополняются новыми комплексами действий. В них включаются вновь возникшие следственные версии, требующие дополнительной проверки.

Принцип индивидуальности. Индивидуальность планирования обусловливается как неповторимостью каждого из расследуемых преступлений, так и особенностями личности следователя, осуществляющего эту деятельность. Каждый план должен строиться только на тех данных, которые получены в ходе конкретного следствия.

Принцип конкретности планирования состоит в том, что разрабатываемые планы не должны иметь общих формулировок. Содержащаяся в них программа призвана дать предельно четкие ответы на основные вопросы: цель планируемых действий, кто, в какие сроки, где и когда будет осуществлять эти действия. 
В зависимости от этапов расследования различают следующие виды планирования:

- планирование первоначального этапа следствия;

- планирование последующего этапа;

- планирование на заключительном этапе.

На каждом из указанных этапов процесс расследования имеет особенности, обусловленные главным образом содержанием и объемом исходной информации, которой располагает следователь, спецификой решаемых задач. Деятельность по планированию также приобретает отличительные черты в зависимости от видов организации расследования по конкретному делу: осуществляется расследование одним следователем или следствие поручено группе (бригаде) следователей.

Планирование первоначального этапа расследования, в первую очередь, предопределяется спецификой решаемых на этом этапе задач. Задачами первоначального этапа являются:

Ориентирование в обстоятельствах совершенного преступления.

Поиск доказательств и источников их получения.

Установление и розыск преступников по горячим следам.

Выяснение причин и условий, способствовавших совершению конкретного преступления.

Решение этих задач требует быстрого проведения комплекса действий, не терпящих отлагательства и носящих поисковый характер. В ряде случаев эти действия должны осуществляться одновременно, причем результаты их часто зависят от максимального использования факторов внезапности. Возникает необходимость подключения сил и средств, которыми располагают службы органов внутренних дел, и согласования их действий с действиями следователя.

В этих условиях приобретает особое значение организация планирования расследования.

Одной из специфических черт планирования первоначального этапа расследования является широкое использование на этом этапе различного вида типовых планов, основанных на научном обобщении практики правоохранительных органов по борьбе с преступностью, в частности, по расследованию отдельных видов преступлений.

К таким планам относятся:

a) планы проведения комплексных операций при совершении определенного вида особо опасных преступлений; 
б) перечни неотложных следственных действий и оперативно-розыскных мероприятий, осуществляемых при поступлении сообщений или заявлений о совершении преступлений;

в) программы действий следственно-оперативной группы, выезжающей на место происшествия

Наличие такого рода планов и перечней действий не исключает необходимость принятия решений о направлении следствия, об объеме и последовательности действии с учетом постоянно поступающей в ходе следствия информации.

При решении вопроса о последовательности осуществления следственных и иных действий учитываются следующие моменты:

Необходимость сохранения и обеспечения подлинности объектов путем производства в первую очередь тех следственных действий, которые направлены на обнаружение и фиксацию быстро исчезающих следов или исследование изменяющейся со временем обстановки места происшествия (к этой группе относятся действия, неотложность которых предопределена иными исключительными обстоятельствами: например, допрос умирающего потерпевшего);

Учет регламентированных законом сроков проведения определенных процессуальных действий: задержания, предъявления обвинения, допроса обвиняемого и другое;

Возможное влияние отдельных процессуальных действий на процесс производства по уголовному делу (наложение ареста на имущество или избрание меры пресечения);

Длительность периода осуществления отдельных действий (экспертизы, ревизии);

Возможность проверки путем производства того или иного действия сразу нескольких следственных версий.

Процесс планирования первоначального этапа расследования имеет существенные особенности в тех случаях, когда решение о возбуждении уголовного дела принимается на основе анализа материалов, полученных оперативным путем. В этом случае с самого начала расследования составляются подробные, детально разработанные планы. Им предшествует тщательное изучение материалов, полученных оперативным путем. Анализ этих материалов дает возможность ознакомиться с оперативно-розыскными версиями, решить вопрос о том, какие источники доказательств установлены и могут быть 
использованы в ходе следствия, a какие обстоятельства требуют дополнительного уточнения. Полезно составить конспект по изученным материалам, систематизировать в той или иной форме установленные данные. Требуется согласовать с оперативными работниками сроки проведения планируемых действий, определить конкретных исполнителей этих действий, установить способы обмена полученной информацией. Особое внимание уделяется разработке тактики производства тех следственных действий, осуществление которых может повлечь разглашение сведений, полученных оперативным путем.

Результатом проделанной работы является составление согласованных между собой планов: плана следственных действий и плана проведения оперативно-розыскных мероприятий. Каждый план утверждается начальником соответствующего подразделения органов внутренних дел.

Если в результате изучения собранных оперативным путем данных принимается решение о необходимости возбуждения уголовного дела и проведении следствия группой следователей, процесс планирования будет иметь специфику, определяемую данным методом расследования. Решение о комплектовании группы следователей может быть принято и на других стадиях расследования, что, однако, не оказывает существенного влияния на процесс планирования при групповом методе следствия.

Производство расследования группой следователей допускается законом в двух случаях: 1) при сложности дела или 2) при большом объеме материалов.

В обоих случаях сложно одновременно провести большое количество следственных и иных действий с учетом требований полноты, всесторонности и объективности следствия, проводимого в установленные законом сроки.

В силу объективных факторов один следователь по такого рода делам не в состоянии обеспечить проведение эффективного расследования в предельно сжатые сроки с соблюдением всех процессуальных требований. Поэтому создание следственных групп и проведение расследования бригадным методом в рассматриваемых случаях является необходимым условием эффективности следствия.

При соблюдении указанных требований закона в случае расследования, проводимого группой следователей, создаются предпосылки для проведения расследования в полном соответствии со всеми принципами уголовного процесса, проявляющимися в стадии предварительного следствия; необходимо особо подчеркнуть мысль о том, что используемый в криминалистической 
литературе термин «бригадный метод расследования» предполагает наличие бригады, состоящей исключительно из следователей. В состав группы могут быть включены следователи разных органов внутренних дел.

Такая структура бригады целесообразна тогда, когда следственные действия по расследуемому преступлению будут осуществляться в разных, отдаленных друг от друга пунктах. Включение в состав группы следователей, которые обслуживает соответствующие пункты, исключает необходимость лишних поездок.

Поскольку групповой метод расследования используется тогда, когда речь идет о сложных делах, естественно, что в процессе следствия по такого рода делам не исключается, а, наоборот, имеет особое значение правильное взаимодействие с оперативными работниками.

На стадии реализации оперативных мероприятий большое значение имеет совместное планирование следственных действий и оперативно-розыскных мероприятий. Составляется специализированный план, который согласовывается с их непосредственными начальниками и утверждается руководителем органа, производящего расследование.

План в обязательном порядке должен включать в себя: розыскные и следственные версии; данные, подлежащие установлению для их проверки; перечень следственных действий; обстоятельства, подлежащие установлению оперативным путем; сроки и исполнители.

Таким образом, можно сделать вывод, что планирование и выдвижение версий является неотъемлемым этапом расследования преступлений о взяточничестве. Это позволяет распределить усилия по раскрытию преступления в зависимости от специфики деятельности того или иного подразделения, а также четко выделить действия по раскрытию преступления. 
1. Аверьянова Т.В., Белкин Р.С., Корухов Ю.Г., Россинская Е.Р. Криминалистика. Учебник для вузов. Под ред. Заслуженного деятеля науки Российской Федерации, профессора Р.С. Белкина. - М.: Издательская группа НОРМА-ИНФРА-М., 1999. -990с.

2. Белкин Р. С. Криминалистика: проблемы, тенденции, перспективы. От теории к практике. - M., 1988.

3. Быстров Н. Г. Взяточничество. Методика расследования. - М., 1963.

4. Каминский М. К. Расследование взяточничества. - М., 1999.

5. Криминалистика. Расследование преступлений в сфере экономики. - Нижний Новгород, 1995.

6. Конституция Республики Казахстан от 30 августа 1995 г. (с измене-ниями от 7 октября 1998 г.). - Алматы, 1995. - 40 с.

7. Манахов С.А. Расследование преступлений о коррупции // Закон и право. 2004. - № 9.

8. Уголовный кодекс Республики Казахстан (по состоянию законодательства на 2015 г.) Юридический справочник «Законодательство»: [Электронный ресурс]. 